\title{
The Development Trend of Snow and Ice Sports Industry in Heilongjiang Province under the New Normal Condition
}

\author{
Ma Baofa ${ }^{a}$, Wu Tienan \\ Heihe University School of Physical Education, Heihe 164300, China \\ amabaofahh@126.com
}

Keywords: New normal; Heilongjiang province; Snow and ice sports industry; Development trend

\begin{abstract}
The snow and ice sports industry has always been a trump card in Heilongjiang province. The promotion of snow and ice culture, the ice and snow tourism industry, the development of ice and snow sports, and the deepening of snow and ice manufacturing are all the advantageous projects in the snow and ice industry of Heilongjiang province. Under the new normal study of ice and snow sports industry in Heilongjiang province, it can be found that the advantage of ice and snow sports industry development is the natural environmental advantage with strong cultural atmosphere, the policy environment, the equipment manufacturing industry base and so on. This paper put forward cultivating talents, ice and snow industries guiding ideas, and set up the ice and snow manufacturing development strategy of the growth strategy of innovation, conducive to regional economy and the rapid development of ice and snow sports industry in Heilongjiang province.
\end{abstract}

\section{Introduction}

\subsection{The new normal}

Since the new leadership of the CPC central committee took office, the concept of China's economy entering the "new normal" has been put forward in combination with China's economic development stage and global economic pattern changes. China first proposed and clarified the concept of "' new normal" "at the central economic work conference held in 2015. Xinhua news agency has issued about xi general secretary in terms of economic development put forward the important point of the article, the article first mentioned the word "three periods of superposition", three periods including the growth of economic development in China, phase shift and structural adjustment of labor, economic policy digestion phase three parts before, this is central in the economic development in China to make objective and scientific judgment. [2]

The connotation of "new normal" is to pay great attention to improving economic efficiency, reducing production cost and promoting sustainable development. This fully reflects that China's economy will gradually slowdown in the future development process, accelerate industrial structure innovation and upgrading, and change the traditional economic system to take innovation as the driving force of economic development. The term "growth shift period" here means that China's economic development has shifted from rapid growth to moderate growth. "The painful period of structural adjustment" refers to the urgent reform of economic system. Only innovation can promote sustainable development. "The previous stimulus policy digestion period" said that in the current world financial crisis, China adopted a series of measures to stimulate the economy, the current series of measures are in the digestion stage. Based on the above analysis, it is concluded that the optimal range of activities for economic development does not cross the "upper limit" or lower the "lower limit". [3] The so-called "ceiling" means avoiding inflation, and the "lower limit" means maintaining stability and promoting development.

Therefore, under the "new normal", the structure of China's economic growth is continuously improving, the quality of growth has been improved, the new impetus generated within the economy has gathered, the new economic component is thriving, and China's economy is developing to a good prospect. 


\subsection{Definition of sports industry}

The marketization of China's sports industry started around 1980. China's sports industry only gradually developed in the mid-1990s. At this time, sports supplies, sports lottery, sports tourism and sports advertising, and other industries appeared, the development was rapid. However, due to the complexity of the sports industry and the concept of the sports industry, the domestic academia has not yet unified. As early as 1995, the general administration of sport of China issued the outline for the development of sports industry from 1995 to 2010, which pointed out that the sports industry is the aggregation of the same kind of economic activities and the sum of similar economic ministries. Specifically, it includes activities in three aspects: 1. It refers to sports business activities that give play to the economic function and value of sports, namely sports subject industries, such as sports competition performance, training, fitness and training; 2. 2. Sports related industries, such as the production and operation of sports supplies and sports equipment, etc.; 3 . The ministry of sports shall carry out other industrial activities aimed at subsidizing the development of sports undertakings. [4] Our country has expert to divide sports industry concept into broad sense and narrow sense.

\subsubsection{The concept of generalized sports industry}

The first view is to define the sports industry as: "sports industry is the operation of the socialist market economy system of sports undertakings". The emergence and development of sports industry has opened up the vision of sports cause, clarified the thinking of sports work and enhanced the vitality of sports cause development, which has important practical significance and guiding value for promoting the development of China's sports cause. So, what's the difference between the sports industry and the sports industry? The main task of sports undertakings is to meet the needs of social spiritual civilization, pay attention to social benefits and have the nature of public welfare and welfare. The sports industry is different. It is an industry that aims to provide public sports services and products to the society and obtain certain profits. Its main purpose is to seek profits. [5] Under the background of the gradual perfection of socialist market economy, sports industry comes into being with the development of social economy and the improvement of people's living standards.

\subsubsection{The narrow concept of the sports industry}

$\mathrm{Hu}$ defined the sports industry as: "the sports industry refers to the part of the sports industry that can both enter the market and make profits". Therefore, it requires us to put sports into the normal schedule, which is the socialist market economic track. With the establishment of socialist market economic system, China's frequent exchanges with the international community, social and economic development, and the external environment required by the development of China's sports industry have become mature. Therefore, the sports industry should adapt to The Times and have its own complete set of policies, management systems, laws and regulations and other systems. In 1985, the state council listed the sports industry as the third industry for the first time, and regarded it as a new growth point of China's economic development and the pillar of the $\mathrm{H}$ industry according to the development prospect of the sports industry. [6] However, the sports industry is not isolated. The king industry is related to the first industry and the second industry. In developed countries, the sports industry has become a highly mature industry, contributing to the national economy. China has also included the development of sports industry in the "12th five-year plan" and "13th five-year plan" for the development of sports industry, and formulated specific goals and tasks.

\subsubsection{The classification of sports industry}

The development of China's sports industry probably experienced the following stages: the first stage was from 1979 to 1991, which can be summarized as "sports stage, economic and trade performance". Its focus is on economics, not sport; The second phase was from 1992 to 1996; In the context of the establishment of the socialist market economic system, the sports industry has 
entered the stage of development. During this period, the sports industry such as sports competition market, sports lottery, TV and sports paid service was formed. Stage H is from 1996 till now, the sports industry has formed a huge scale through market financing and capitalization.

\section{Current status of snow sports tourism in Heilongjiang province}

\subsection{Development status of snow and ice sports tourism projects in Heilongjiang province}

\subsubsection{Development of leisure, entertainment, sports and fitness projects}

Ice and snow sports tourism project has a strong entertainment and view and admire a gender, such as sports include skiing, ice skating, sledding, too, the dog pull sledge, deer sledge, snowmobile, motorcycle on the ice, ice gyro, football, winter swimming, hunting, snow BingHuaTi, etc., and the Olympic winter games, the world university winter games, such as events, its strong novelty, recreation and appreciation to become one of the largest audience in the world. Competitive sports, with its rich connotation and indomitable fighting spirit, promotes the communication between people and enriches their feelings. Through watching competitive sports, people can experience the enjoyment of beauty, such as the health of the human body, lines and skin color; The beauty of form, rhythm, strength and softness of movement; The united beauty of behavior, never give up, aggressive beauty and brave fighting beauty. Through the appreciation of competitive sports can cultivate the sentiment, beautify the soul, open the wisdom, and perfect the personality.

\subsubsection{Development of traditional folk projects}

Folk ice sports tourism mainly refers to the unique living habits and cultural traditions of local nationalities. For example, the traditional skiing and hunting of Oroqen and he Zhen people, and the traditional skating of daur people, etc. As the folk sports have strong regional characteristics and unique national traditional culture characteristics, with strong uniqueness, barriers and attractions. It further stimulates the interest and motivation of travel lovers to explore and understand the destinations, and further enriches people's experience and increases their knowledge through appreciation and participation.

\subsection{Resource status of snow and ice sports tourism in Heilongjiang province}

\subsubsection{Status of natural resources}

Heilongjiang province, located in the northeast of China, is China's northernmost province with the highest latitude. It is between $135^{\circ} 11^{\prime}$ - east longitude $121^{\circ} 05^{\prime}$, north latitude $43^{\circ} 26^{\prime}-55^{\circ} 33^{\prime}$, the question of development of ice and snow sports tourism has advantageous geographical position and ice and snow resources advantage, is a truly beautiful snow. Heilongjiang unique geographical environment, terrain diversity, there are mountains, valleys and plains, the north-south high, something low terrain characteristics, winter snowfall in Heilongjiang province, a few local temperatures is appropriate, good ecological environment, slope is moderate, stable snow cover, types, snow XueQi for up to six months, snow time in more than 100 days, for the development of ice and snow sports provides a good natural environment. For example, the annual snow days in Harbin, Qiqihar, Mudanjiang, Jiamusi and Suihua areas in Heilongjiang province are basically maintained at 120 to 140 days, while the annual snow days in yichud and Daxinganling areas can be as high as 160 to 200 days, and the snow in mountainous areas can reach $100-130 \mathrm{~cm}$.

\subsubsection{Status of humanistic tourism resources}

Heilongjiang province is a gathering place of ethnic minorities, which mainly includes 10 ethnic minorities living in the world, including manchurian, Mongol, daur, ximen, oroqen, hezhe and ewenki. Each ethnic group has traditional winter sports activities with different customs and characteristics, such as the traditional skiing and hunting of ewenki, oroqen and hezhek. The traditional skating of ethnic minorities in manchu, xibo and daur, etc., all of these ice and snow sports with unique national characteristics have the potential to develop into ice and snow tourism 
resources.

Heilongjiang province established a ski training base in Yuquan as early as the 1960s, established an ice lantern fair in 1963, and then held an ice and snow festival in Harbin in 1985. The international ice and snow festival held in Harbin is the first regional festival in the history of China with ice and snow activities as its content. During the ice fair, snow fair, winter clothing exhibition, snowfield football game, winter swimming and other local characteristics of a series of sports activities with strong fun, high quality economic and trade activities.

\section{Heilongjiang province ice and snow sports industrial chain structure}

\subsection{Industry structure}

"The industrial structure of the industry is a combination of all the production industries within the national economy in the process of social reproduction. In the structure of sports industry, each branch industry and each department have certain relevance. [7] It shows the interlocking and feedback effects between the various elements of the sports industry, between the structures, between the elements and the structures. According to this correlation, the snow and ice sports industry can be divided into core industries such as ice and snow sports performance industry, related industries such as ice and snow sports supplies, and peripheral industries such as ice and snow sports media. Correspondingly, as a sub-class of the sports industry, the industry sectors, branches and sub-industries that constitute the structural chain of ice and snow sports industry are also interconnected and influencing each other. This is because the sports industry between the internal structure of the elements and some degree of chain and feedback, for example, the rapid development of the core industry to a certain extent, and so did the relevant industries and the development of peripheral industries, the development of peripheral industries is the premise of the development of the core industry, the development of peripheral industries and the development as the core industry and related industry the external environment, better able to promote the development of relevant industries and the core industry, the development of related industries as the core industry and the development of peripheral industries provide the material conditions.

\subsection{Consumption structure}

\subsubsection{Connotation of consumption structure}

Economists Carolina, (M.K alecki) is also clearly pointed out that the consumption structure of industrial structure effect, he thought, "in the mastery of productive and unproductive investment and inventory, on the basis of the increase, if and mastered the consumption quantity and structure, can roughly estimate the demand, which can determine the industrial structure". "Consumption and production directly, production is also direct consumption" this statement is put forward in the introduction to the political economics criticism, he also proposed many arguments demonstrates the consumption and production has a high degree of unity, using the large amount of space from different angles expounds the consumption, production, exchange, distribution, the correlation between. Also pointed out that there is a direct link between supply and consumption, that is a kind of social production and consumption behavior, their interdependence is reflected in the medium of any one party to the other side, is each other, the relationship between the two clever metaphor into "movement", sex with each other in the campaign, both, but each in a separate environment. "Production creates material for consumption as an external object; Consumption creates the inner object for production, the need for purpose. Without production there is no consumption, and without consumption there is no production. Therefore, the development of snow and ice sports industry is inseparable from consumption. The industrial structure of snow and ice sports is to produce sports products, including tangible products and intangible products, to meet the needs of the public in the structure of snow and ice sports consumption. Under the conditions of market economy, from the perspective of commodities, the price structure of commodities in the market shows the market supply and demand structure of the industry, and then reflects the consumption structure of snow and ice sports industry. 


\subsubsection{Consumption structure of snow and ice sports industry chain in Heilongjiang province}

According to statistics, "the consumption of sports services and sports information of Chinese residents only accounts for about $10 \%$ of the total sports consumption." In the last century, China's relatively low development level of productive forces, in this economic climate, food and clothing problems are the priorities for the development of the target, people of ice and snow sports consumption is only on the ice and snow sports physical, and consciousness of ice and snow sports labor service consumption, ice and snow sports physical consumption and ice and snow sports labor service consumption imbalance, and the gap is very big, further led to the Heilongjiang province of ice and snow sports consumption structure is not reasonable. The incongruity between physical and labor services consumption in ice and snow sports is shown as follows: in economically developed regions, the share of physical consumption in ice and snow sports is more than $60 \%$, while that in snow and ice sports is only more than 30\%. In regions with relatively backward economic development, the market share of physical consumption of ice and snow sports is $80 \%$, while the consumption of snow and ice sports labor service is only $20 \%$. After entering the new century, the economic level has been further improved, but the consumption structure of snow sports in Heilongjiang province has not changed much.

\section{Conclusion}

The "new normal" of China's economy has provided new opportunities and challenges for industrial development in different fields. The snow and ice sports industry has always been a trump card in Heilongjiang province. The promotion of snow and ice culture, the ice and snow tourism industry, the development of ice and snow sports, and the deepening of snow and ice manufacturing are all the advantageous projects in the snow and ice industry of Heilongjiang province. In the process of developing the snow and ice industry, we should adhere to the concept of "innovation in development and development in innovation", play the ice and snow card well, and turn "cold resources" into "hot industry". Heilongjiang province, as a big snow and ice province, needs to seize opportunities and meet challenges under the new normal.

\section{Acknowledgement}

The annual project of Heilongjiang Philosophy and Social Science Research Program(Support and Construction):The Construction of Business Models of the Ice Snow Sport Industry in Heilongjiang Province (Number:18TYE555).

\section{References}

[1] Chang zhi, discussion on China's sports management system [J]. Journal of Guizhou normal university, 2016 (2): 15-19.

[2] Sun lei Ming, thoughts on the reform of competitive sports system in China [J]. Journal of Wuhan sports university, 2002, (1):22.

[3] Sun hanchao, qin stink Lin. Course of sports management [M]. Beijing: people's sports press, 1996.

[4] Zhang yongtao, the new normal of China's sports industry development: features, challenges and transformation [J]. Sports and science, 2015, 36 (5): 22-27.

[5] Wang xiaodong et al. Development orientation and path thinking of China's leisure sports under the new normal [J]. Journal of jilin institute of physical education, 2016, 32 (1): 9-12.

[6] $\mathrm{Hu}$ ke promoted the development of sports in the process of understanding and conforming to the new normal [J]. Journal of sports adult education, 2015, 31 (5): 29-32. 